\title{
MECHANISM OF THE INHIBITORY ACTION OF NaF AND Na-FLUOROACETATE ON THE CARDIAC FUNCTION AND THE CARBOHYDRATE METABOLISM OF THE ISOLATED BULLFROG'S HEART
}

\author{
Koroku Hashimoto* \\ Department of Pharmacology, Faculty of Medicine, University of Tokyo, Tokyo and \\ Iatrochemical Institute of the Pharmacological Research Foundation, Inc.
}

The heart of the cold blooded animal has a characteristic feature of the carbohydrate metabolism as clarified on the isolated bullfrog's heart in the previous papers ${ }^{1,2}$, which is summerized as follows: 1) The lower blood glucose level but the higher blood lactate level is a normal finding. 2) The cardiac tissue allows the accumulation of glycogen to a very high level. 3) The Crabtreelike effect is observed, i.e., the diminution of the oxygen consumption is induced by addition of glucose into the perfusing blood, while the lactate augments the oxygen consumption. There is no difference in the effect on the cardic function between addition of glucose and lactate, both of which improve the cardic function. 4) The scope of the oxygen consumption relates to the ratio of the lactate uptake and the lactate plus glucose uptake. Furthermore ElLIs ${ }^{3)}$ showed clearly the characteristic metabolic state of the frog's heart when the observed the reappearance of the inotropic action of cardiac glycoside on the frog's heart treated with fluoroacetate by adding the glucose in the perfusing Ringer solution. In contrast, the higher glucose uptake and also the higher lactate uptake related to the higher oxygen consumption is common feature of human and dog's heart.4,5) The fluoroacetate treatment blocks the inotropic effect of cardiac glycosides on the cat's papillary muscle ${ }^{6)}$ and on the dog's heart-lung preparation in the adequate glucose supply.7) All of these observations suggest directly or indirectly that the oxydative process is quite dominant in the cardiac tissue of the warm blooded animal, while the powerful enough Embden-Meyerhof system to supply the energy for the normal cardiac function and further for inducing the inotropic effect of drugs flourishes in the cardiac tissue of frog. The arterial blood not only of the hibernated animal but also of the awaken one is quite dark. Then it can be said that the anerobic condition is not peculiar nor unphysiological for bullfrogs and the heart of this species of animal is a convenient material to know in what extent glycolysis and respiration take part and react in the physi-

Received for publication November 2, 1960.

* 㭼本虎六 
ological and pharmacological conditions. The studies on the effect of the metabolic inhibitors on the cardiac function of the cold blooded animal help not only to understand the mechanism of the action of effective drugs but also to find an answer to the above question. Author selects in this experiment sodium fluoride and fluoroacetate respectively for the inhibition of glycolysis and respiration..

\section{PROCEDURES}

The male and female bullfrogs, weighed 180 to 250 gr. were used. The animals were fed in the open air water pool with young alive cray-fishes for more than two weeks (after delivery from the animal dealer) in the summer, while they were kept in $20^{\circ} \mathrm{C}$. water bath under the electric lamp light for two days, bringing them into the perfectly awaken state from the hibernation in the winter.

The isolated bullfrog's heart ${ }^{1}$ ), set up in the double cannula preparation, perfusing $2 \mathrm{ml}$. of the heparinized blood taken from the animal before isolation $(5-7 \mathrm{ml}$. of the blood was able to be drained from one animal), tied up at the 'sinoatrial boundary and hanged in the modified Clark's bulb which was kept in the water bath at $20^{\circ} \mathrm{C}$., was driven by the electric stimulator in the constant rate of 20 per minute. The air inside the bulb is replaced by the air-oxygen mixture half and half.

For the nourishment, $0.02 \mathrm{ml}$. of the $0.5 \mathrm{M}$. glucose and lactate solution was added to $2 \mathrm{ml}$. of the blood to avoid the modification due to the wide variation in the blood sugar and lactate level of animals on the metabolism of the heart as possible. $0.4 \mathrm{mM}$. $\mathrm{Na}_{2} \mathrm{HPO}_{4}$ was also added in the blood for improving the glucose uptake.

Experiments were designed in two ways as follows:

Arrangement for the first part of experiments: Drugs were dissolved freshly in the frog's Ringer solution. $0.02 \mathrm{ml}$. of the drug solution was measured by the micropipet and placed on a tiny plate fixed at the tip of the needle of syringe which was installed air-tightly with vacuum grease on the lid on the bulb. The drug solution was administered into the venous cannula by turning around the syringe and bringing the plate directly into the blood stream from the outlet of the aortic cannula at the time when the control observation for one hour was finished. The effects of drugs were observed for following two hours.

Arrangement for the second part of experiments: Two hours perfusion was repeated twice on the same heart successively, measuring the blood glucose, lactate and pyruvate levels at the beginning and the end of each perfusion trial. The oxygen consumption, the carbonic acid production and the cardiac output were measured during a later one hour period in the course of 2 hours perfusion. In the control experiments each trial was arranged in just the same fashion, although the glucose, lactate and pyruvate levels in the blood for the second trial differed very slightly from these levels for the first one by preserving the blood in the ice box. The arrangement for observing the effects of drugs was as follows: the first trial was done without drugs exactly same as in the control experiment and the second one was perfused with the blood to which the drug solution was added in the one hundredth of the blood volume in advance.

For evaluation of the results on the effects of drugs, the differences of the blood pyruvate level, the glucose- and lactate uptake, the oxygen consumption and the cardiac 
output between the first and second perfusion trials were judged by the $t$-test between the control and treated experiments.

\section{RESULTS}

\section{First part of experiments;}

1. Control: $0.02 \mathrm{ml}$. of Ringer solution, one hundredth of the circulating blood volume, was added in place of the drug administration. The oxygen consumption and the cardiac output were diminishing gradually for around 20 per cent at the end of two hours perfusion. A typical result was shown in Fig. 1.

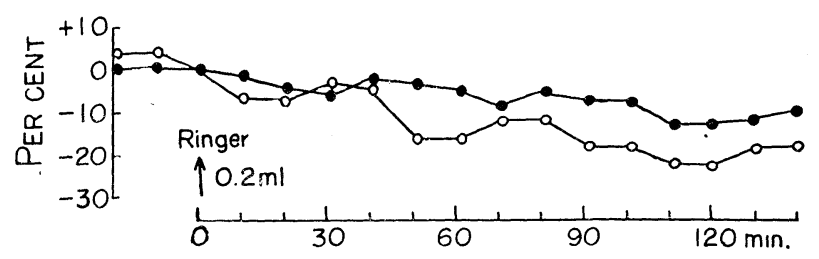

FIG. 1. Control experiment. The heart rate, $20 / \mathrm{min}$.; the temperature, $20^{\circ} \mathrm{C}$. The initial oxygen uptake, $1.853 \mathrm{ml} / \mathrm{g} / \mathrm{h}$. The initial cardiac output, $3240 \mathrm{ml} / \mathrm{g} / \mathrm{h}$. Clear circles represent the oxygen uptake; filled circles, the cardiac output.

2. Sodium fluoride: Fluoride was given in the final concentration of 0.005 to $0.02 \mathrm{M}$. The heart contracted more completely soon after fluoride solution was administered in the $0.005 \mathrm{M}$ concentration (FIG. $2 \mathrm{a}$ ). The same feature was observed also (in the 0.01 to $0.02 \mathrm{M}$ ), meanwhile the diastolic relaxation was definitely limited. Thus the cardiac output diminished due to the imperfect filling of the ventricle in the higher concentration. On the other hand the oxygen consumption increased gradually above the initial level in the $0.01 \mathrm{M}$ (FIG. 2 b), while it diminished initially and then converted to increase far above the initial level in a higher concentration $(0.02 \mathrm{M}$.). Typical results were shown in FIG. 2 c.

3. Sodium fluoroacetate: Fluoroacetate was given in the final concentration of 0.001 to $0.01 \mathrm{M}$. The ordinary experiments were done in the heart rate of 20 per minute and in $20^{\circ} \mathrm{C}$., but for testing the effect on the state of higher demand of energy, the rate of contraction rose up to 40 per minute and the environmental temperature up to $25^{\circ} \mathrm{C}$.

The rapid and profound diminution of the oxygen consumption was observed in the $0.01 \mathrm{M}$. concentration (FIG. $3 \mathrm{a}$ ). Such response was found even in the 0.001 M., but less prominent. The diminution of the oxygen consumption reached maximum within 30 minutes, and then converted to the gradual increase to the initial level by a lapse of one hour and it rose up above the initial level during a following one hour period. The conractile force was not definitely modified, 

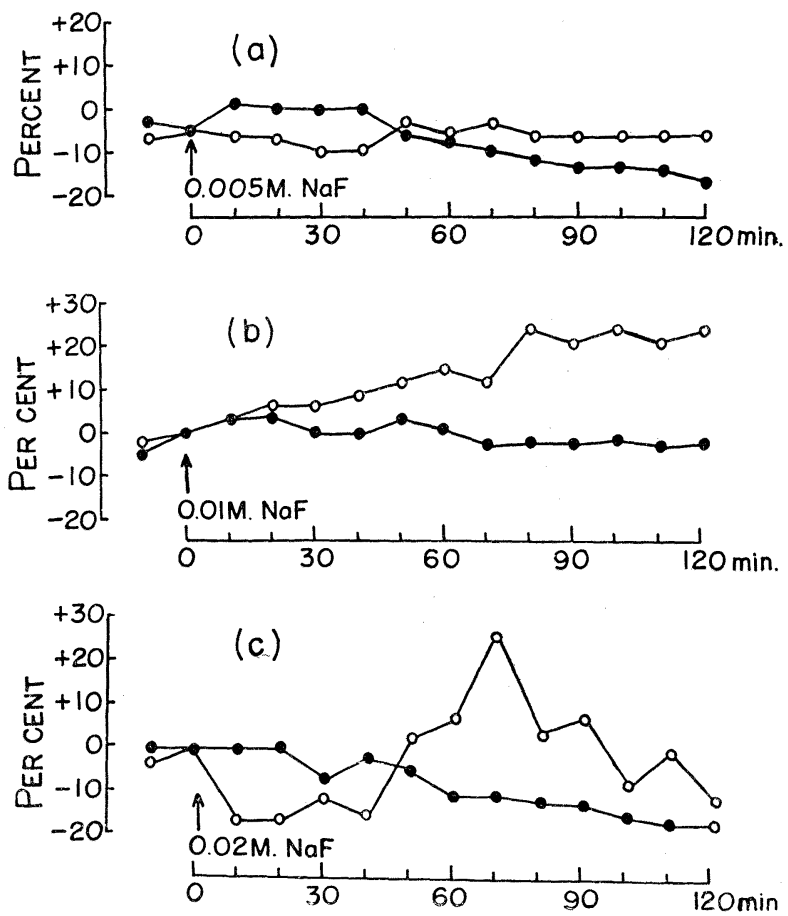

FIG. 2. Effect of sod. fluoride (a) $0.005 \mathrm{M}$, (b) $0.01 \mathrm{M}$ and (c) $0.02 \mathrm{M}$. The heart rate, $20 / \mathrm{min}$; the temperature, $20^{\circ} \mathrm{C}$. The oxygen uptake before drug administration; 1.604 in (a), 0.992 in (b) and $1.560 \mathrm{ml} / \mathrm{g} / \mathrm{h}$ in (c). The cardiac out; 2674 in (a), 1360 in (B) and $1910 \mathrm{ml} / \mathrm{g} / \mathrm{h}$ in (c). Clear circles represent the oxygen uptake; filled circles, the cardiac output.

evenwhen the oxygen consumption was in the maximum diminution, hence the cardiac output increased or decreased within the scope of small variation. However during the second one hour period the heart contracted more completely and the cardiac output increased above the initial level.

In the case of 30 beats per minute at $25^{\circ} \mathrm{C}$., in which the oxygen consumption was higher than in the former condition, the sequence of events were almost same, but the overshoot of the oxygen consumption and cardiac output above the initial level after a lapse of one hour was not observed (FIG. $3 \mathrm{~b}$ ). In the further higher oxygen demand, i.e., 40 beats per minute at $25^{\circ} \mathrm{C}$., the contraction was impaired in parallel with a progress of depression of oxygen consumption soon after fluoroacetate administration, both of which did not recover in the further two hours observation (FIG. $3 \mathrm{c}$ ).

II. Second part of experiments; All data were collected in the TABLE 1.

In control experiments two hours perfusions were repeated twice without drug administration. The glucose uptake reduced in the second trial, the lactate uptake showed a similar tendency but in a lesser degree, while the blood pyruvate 

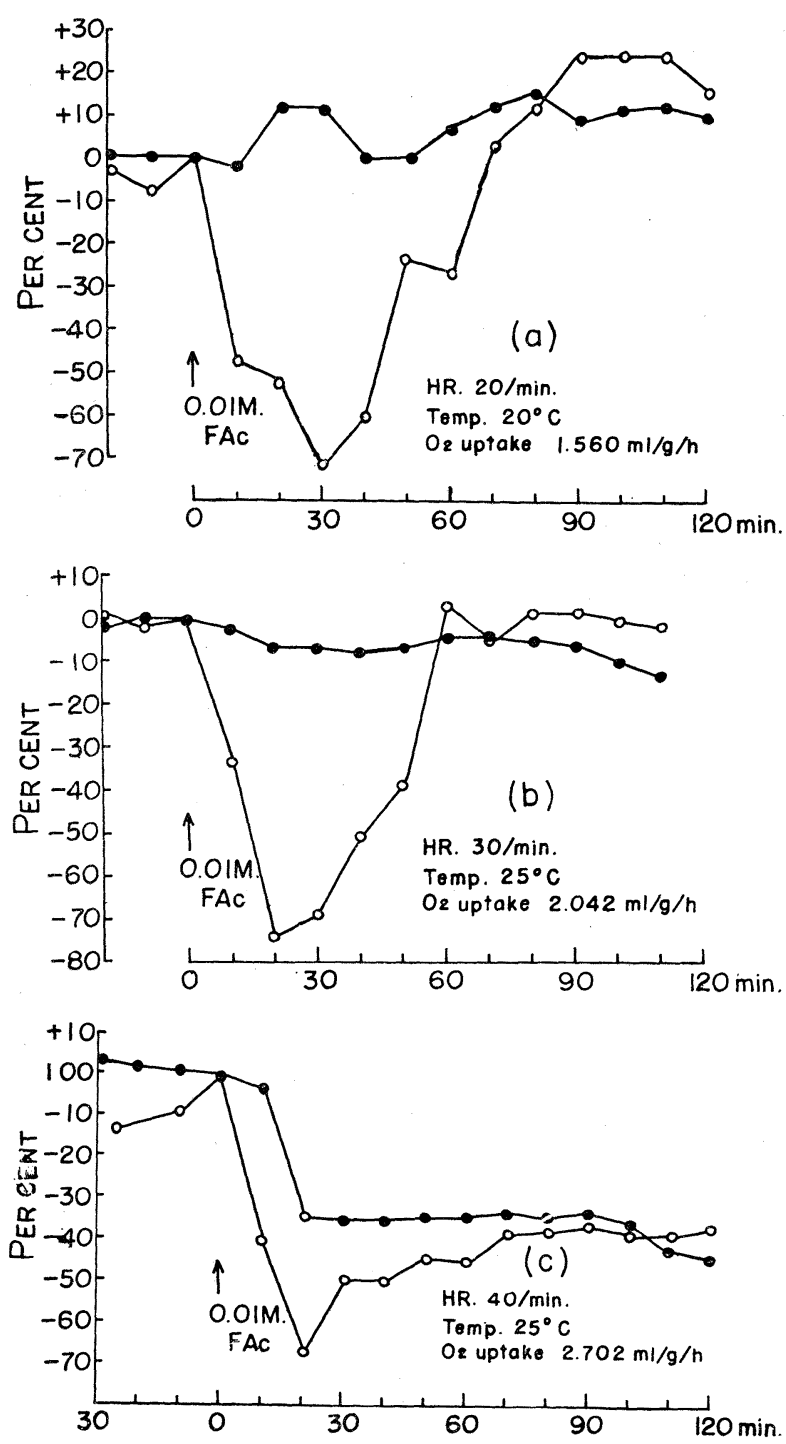

FIG. 3. Effect of $0.01 \mathrm{M}$ sod. fluoroacetate. The heart rate, $20 / \mathrm{min}$. in (a), $30 / \mathrm{min}$ in (b) and $40 / \mathrm{min}$ in (c). The temperature, $20^{\circ} \mathrm{C}$ in (a) and $25^{\circ} \mathrm{C}$ in (b) and (c). The oxygen uptake before drug administration, 1.560 in (a), 2.042 in (b) and $2.702 \mathrm{ml} / \mathrm{g} / \mathrm{h}$ in (c). The cardiac output, 1910 in (a), 2320 in (b) and $2302 \mathrm{ml} / \mathrm{g} / \mathrm{h}$ in (c). Clear circles represent the oxygen uptake, filled circles, the cardiac output.

level at the end of perfusion, the oxygen consumption and cardiac output were almost not changed. RQ value had a decreasing tendency, but the number of experiments was not sufficient enough. 
TABLE 1

The effect of sodium fluoride $(\mathrm{NaF})$ and sodium fluoroacetate (FAc) on the carbohydrate metabolism, the cardiac output, the oxygen-consumption and RQ.

\begin{tabular}{|c|c|c|c|c|c|c|c|}
\hline & \multirow{2}{*}{$\begin{array}{l}\text { No. of } \\
\text { animals } \\
\text { studied }\end{array}$} & \multicolumn{2}{|r|}{ 1st trial } & \multicolumn{2}{|l|}{ 2nd trial } & \multirow{2}{*}{\multicolumn{2}{|c|}{$\begin{array}{c}\text { Signifi- } \\
\text { cance* } \\
\text { by t-test }\end{array}$}} \\
\hline & & \multicolumn{2}{|c|}{ Treatment } & \multicolumn{2}{|l|}{ Treatment } & & \\
\hline \multicolumn{8}{|c|}{ Glucose uptake $(\mathrm{mg} / \mathrm{g} / \mathrm{h})$} \\
\hline Control & 10 & None & $0.313 \pm 0.070$ & None & $0.220 \pm 0.074$ & & \\
\hline NaF. expts. & 9 & None & $0.441 \pm 0.043$ & NaF. 0.01-0. & $0.250 \pm 0.048$ & & $<0.3$ \\
\hline FAc. expts. & 7 & None & $0.362 \pm 0.067$ & FAc. $0.01 \mathrm{M}$ & $0.462 \pm 0.01$ & & $<0.05$ \\
\hline \multicolumn{8}{|c|}{ Lactate uptake $(\mathrm{mg} / \mathrm{g} / \mathrm{h})$} \\
\hline Control & 10 & None & $0.547 \pm 0.123$ & None & $0.466 \pm 0.084$ & & \\
\hline NaF. expts. & 9 & None & $0.732 \pm 0.125$ & NaF. $0.01-0.02 \mathrm{M}^{* *}$ & $0.706 \pm 0.092$ & $\mathbf{P}$ & n.s. \\
\hline FAc. expts. & 8 & None & $0.823 \pm 0.146$ & FAc. $0.01 \mathrm{M}$ & $0.781 \pm 0.134 * * *$ & & \\
\hline \multicolumn{8}{|c|}{ Pyruvate level at the end of 2 hours perfusion $(\mathrm{mg} / \mathrm{dl})$} \\
\hline Control & 6 & None & $2.70 \pm 0.84$ & None & $2.73 \pm 0.54$ & & \\
\hline NaF. expts. & 9 & None & $3.19 \pm 0.56$ & $\mathrm{NaF} .0 .01-0$. & $7.20 \pm 1.20$ & & $<0.001$ \\
\hline FAc. expts. & 8 & None & $3.19 \pm 0.56$ & FAc. $0.01 \mathrm{M}$ & $6.55 \pm 1.55$ & & $<0.001$ \\
\hline \multicolumn{8}{|c|}{ Cardiac output $(\mathrm{ml} / \mathrm{g} / \mathrm{h})$} \\
\hline Control & 8 & None & $1064 \pm 194$ & None & $1032 \pm 216$ & & \\
\hline NaF. expts. & 8 & None & $1476 \pm 149$ & $\mathrm{NaF} .0 .01-0.02 \mathrm{M}^{* *}$ & $1172 \pm 80$ & & $<0.05$ \\
\hline FAc. expts. & 5 & None & $1392 \pm 64$ & FAc. $0.01 \mathrm{M}$ & $1423 \pm 57$ & & n.s. \\
\hline \multicolumn{8}{|c|}{ Oxygen consumption $(\mathrm{ml} / \mathrm{g} / \mathrm{h})$} \\
\hline Control & 10 & None & $0.793 \pm 0.105$ & Nonə & $0.773 \pm 0.102$ & & \\
\hline NaF. expts. & 8 & None & $0.969 \pm 0.090$ & $\mathrm{NaF} \cdot 0.01-0.02 \mathrm{M}^{* *}$ & $0.966 \pm 0.102$ & $\mathbf{P}$ & n.s. \\
\hline FAc. expts. & 5 & None & $0.914 \pm 0.040$ & FAc. $0.01 \mathrm{M}$ & $0.911 \pm 0.053$ & $\mathbf{P}$ & n.s. \\
\hline \multicolumn{8}{|c|}{$R Q$} \\
\hline Control & 6 & None & $0.98 \pm 0.01$ & None & $0.92 \pm 0.07$ & & \\
\hline NaF. expts. & 7 & None & $0.96 \pm 0.05$ & $\mathrm{NaF} \cdot 0.01-0.02 \mathrm{M} * *$ & $1.07 \pm 0.06$ & $\mathbf{P}$ & n.s. \\
\hline FAc. expts. & 4 & None & $0.95 \pm 0.01$ & FAc. $0.01 \mathrm{M}$ & $1.03 \pm 0.06$ & $\mathbf{P}$ & n.s. \\
\hline
\end{tabular}

* Significance test among control, $\mathrm{NaF}$ - and FAc-experiments for the difference between 1st and 2 nd perfusion trial.

** No. of experiments; 4 for $0.01 \mathrm{M}, 5$ for $0.02 \mathrm{M}$.

*** Lactate production $\mathrm{mg} / \mathrm{g} / \mathrm{h}$.

TABLE 2

Differences in per cent of the glucose and lactate uptake, the pyruvate level, the oxygen consumption and the cardiac output of the 2 nd perfusion trial from those of the 1st trial, which are recalculated from TABLE 1. Sod. fluoride was added in the 2 nd perfusion.

\begin{tabular}{lcccccc}
\hline & $\begin{array}{c}\text { No. of } \\
\text { expts. }\end{array}$ & $\begin{array}{c}\text { Glucose } \\
\text { uptake }\end{array}$ & $\begin{array}{c}\text { Lactate } \\
\text { uptake }\end{array}$ & $\begin{array}{c}\text { Pyruvate } \\
\text { level }\end{array}$ & $\begin{array}{c}\text { Oxygen } \\
\text { consumption Cardiac }\end{array}$ \\
\hline output
\end{tabular}


Fluoride induced definitely a higher blood pyruvate level at the end of perfusion $(P<0.001)$, a significant reduction of cardiac output $(P<0.1)$ and the decrease of glucose uptake $(P<0.3)$, while the increase of lactate uptake was not significant and the oxygen consumption did not change. The changes were more apparent in a higher concentration (0.02 M.) as shown in TABLE 2.

Fluoroacetate induced the increase of glucose uptake $(P<0.05)$, inhibited the lactate uptake, i.e., converted to the lactate production and elevated the blood pyruvate level $(\mathrm{P}<0.001)$. The oxygen consumption and the cardiac output recovered to the control level in a later one hour period of 2 hours perfusion.

\section{DISCUSSION}

It is desirable for the metabolic study to keep the given concentration of metabolic source throughout the experiment. Ringer solution is suitable for this purpose, however Clark reported no utilization of glucose when Ringer solution is perfused in place of blood. The blood perfusion is believed as an indispensable condition for obtaining the whole view of the metabolic process. However blood glucose and lactate levels of animals are very variable and it is not so often to be null at the end of two hours perfusion. In this experiment extra amounts of glucose and lactate with a small amount of $\mathrm{Na}_{2} \mathrm{HPO}_{4}$ are added to the perfusing blood. RACKER and $\mathrm{WU}^{8)}$ reported on ascites tumor cells which have a powerful glycolytic process that the level of inorganic phosphate inside the cell which relates to its level in the surrounding fluid is the limiting factor of the glucose uptake, and the rate of uptake of glucose into the cells is initially very rapid and then stabilized in the slower steady level. Simultaneously, the inorganic phosphate concentration inside the cells is stabilized at the lower level. When the same perfusion experiment is repeated twice as done in the second part of experiments, the rate of glucose uptake is lower in the second trial. This phenomenon could be understandable on RACKER and WU's note on the role of inorganic phosphate for the glucose uptake. The cardiac output and the oxygen consumption are almost similar between the first and the second perfusion trial, therefore the extent of transfer of glucose and lactate from the blood into the cardiac tissue will not directly concern with the total supply of energy for the cardiac function, rather tell the situation of the metabolic process.

The pyruvate level at the end of perfusion is either higher or lower than the initial level, of which tendency is different from heart to heart and from quality to quality of the perfused blood. On the same heart perfused with the same blood the blood pyruvate level at the end of two hours perfusion is almost same between the first and the second trial. Pyruvate is a substance standing on the crossed point between the glycolysis and respiration and an obtained equilibrium between the pyruvate levels inside and outside the cell during circulation with a limited amount of blood are expected, hence the blood pyruvate level helps to 
know also the state of metabolic process.

It is a peculiar feature that the level of pyruvate is definitely high after fluoride is added into the perfusing blood. The higher pyruvate level is found also after the fluoroacetate treatment. In this case the oxydative process is inhibited, the lactate is not utilized and the lactate level actually elevates. Hence the elevation of pyruvate level is an easily understandable sequence. However, in the case of fluoride the lactate level is not elevated and the lactate is still utilized. Then the elevation of the blood pyruvate level should be explained on the other point. Under the inhibitory effect of fluoride on the Embden-Meyerhof system, the accumulation of lactate by hydration of pyruvate does not occur, then the equilibrium in the lactic dehydrogenase equation is shifted to the dehydrogenation of lactate to pyruvate. It will be a principal reason for the elevation of the pyruvate level.

However there is an unexpected result of not so definite significance $(\mathrm{P}<0.3)$ on the change of the glucose utilization following 0.01 to $0.02 \mathrm{M}$ fluoride. It brings a doubt whether the fluoride could penetrate through the cell membrane for producing its inhibitory activity. The treated bullfrog's heart with $0.02 \mathrm{M}$. fluoride is losing its contraction soon after the initial slight enhancement in the nitrogen atmosphere, while non-treated heart keeps its contractile force for over one hour with elevation of the blood lactate level. $0.005 \mathrm{M}$ fluoride has no influence and $0.01 \mathrm{M}$. shortens the time course to around half an hour. There might be a difference between the inhibitory effects on aerobic and anaerobic glycolysis, however referring the effect on the anerobic condition, it is probable that fluoride in a higher concentration can penetrate through the cell membrane and produces an inhibitory effect on the glycolysis, even if one part would be fixed at the cell membrane as calcium fluoride.

$\mathrm{Mg}{ }^{\cdots}$ is the indispensable ion for the enzyme activity in the glycolysis and it is understood that the inhibitory activity of fluoride is induced by Mg-fluorophosphate formation. The concentration of the inorganic phosphate modifies actually the inhibitory activity of fluoride, as MeyerhoF and Schulz ${ }^{9)}$ (1938) showed that even $0.1 \mathrm{M}$. fluoride does not inhibit the glycolysis in the phosphate free medium. Furthermore $\mathrm{Mg}^{-}$" is also indispensable for the muscle relaxing factor (KEILly-MEYERHOF's ATPase) which exists in the endoplasmic reticulum of the skeletal muscle ${ }^{10)}$. Therefore fluoride would inhibit also the muscle relaxation. Although the relaxing factor is not yet purely extracted from the cardiac tissue, it is expected that the grade of the inhibition of the glycolysis and the restriction of the diastolic relaxation should be parallel, when fluoride immigrates inside the cardiac tissue through the cell membrane.

An inotropic effect of sodium fluoride like the cardiac glycoside is observed on frog's hearts (LoEwI ${ }^{11)}$ and cat's papillary muscle ${ }^{6)}$. The same sequence is found on the bullfrog's heart which is perfused with the blood of the same animal. On this preparation the lower concentration $(0.005 \mathrm{M})$ of fluoride induced the 
more complete contraction, while the higher concentration brought a gradually decreasing cardiac output due to restriction of the diastolic relaxation. As shown in TABLE 2, the grade of inhibition of the glycolysis, i.e., the decrease of the glucose uptake, the increase of the lactate uptake and the blood pyruvate level, is almost in accordance with the extent of the diminution of the cardiac output. Therefore the inhibitory mechanism of glycolysis and diastolic relaxation acts probably on the similar process, while the inotropic action in the lower concentration is not connected with the inhibition of glycolysis. It might be due to the membrane effect by being fixed as calcium fluoride as Loewi expected.

As the oxygen consumption is curbed by the diastolic volume, the amount of oxygen consumption is oppositely affected by the restriction of diastolic volume and by the inhibition of glycolysis in the higher fluoride concentration. The augmentation of oxygen consumption observed even in this condition may express the greater dependence of the energy supply on the respiration after the fluoride treatment. In other words, this may be one evidence of the greater dependence of energy supply on the glycolysis in the normal cardiac activity of the cold blooded animal and a normal finding of the high blood lactate level is another supporting evidence.

The depression of the oxygen consumption is rapidly induced by fluoroacetate. All the while there is no peculiar mode of the contraction, when the heart is driven in the given rate. Therefore the glycolytic process takes place probably promptly for convering the total energy demand. It is rather surprising to switch so swiftly and so smoothly the energy supplying system from respiration to glycolysis in the cardiac tissue. The cardiac output is diminishing in parallel with the depression of the oxygen consumption, when the heart rate is double and the environmental temperature is $5^{\circ} \mathrm{C}$ higher than in the ordinary experimental condition. The level of oxygen consumption is the highest in the heart rate of 30 to 40 per minute in general, and it increases in $30-40$ per cent by raising the environmental temperature by $5^{\circ} \mathrm{C}^{13}$ ). As the level of the oxygen consumption indicates roughly the energy consumption, the above observation can be understood by the insufficiency to supply the larger demand of energy in the adequate speed only by glycolysis. KATzung, Rosin and SchNeIDER ${ }^{14)}$ observed that the fluoroacetate treated rabbit's auricle strip is losing its contradictile force remarkably, when it is stimulated in the growing rate. The sequence of events seems to be similar between cold and warm blooded animals, but the difference found also in the fluoroacetate treatment is: in the cold blooded animal which has a powerful glycolytic process can fulfill the energy demand by glycolysis in a bigger extent than in the warm blooded animal, although there is a limit, especially in the higher environmental temperature. 


\section{SUMMARY}

The effects of inhibition of the aerobic glycolysis by sodium fluoride and inhibition of respiration by sodium fluoroacetate on the carbohydrate metabolism and cardiac function were investigated on the isolated bullfrog's heart perfused with the heparinized blood.

$0.005 \mathrm{M}$. fluoride did not show any inhibitory effect but an inotropic effect. 0.01-0.02 M. fluoride induced the inhibition of aerobic glycolysis, i.e., the definite elevation of the blood pyruvate level at the end of 2 hours perfusion, the increase of oxygen consumption and the decrease of glucose uptake, and simultaneously the decrease of cardiac output due to the restriction of diastolic relaxation. The same mechanism is suggested on the inhibition of glycolysis and the restriction of diastolic relaxation as $\mathrm{Mg}$-fluoro-phosphate formation inside the cell, while the inotropic effect in the lower concentration may be due to the effect of calcium fixation on the cell membrane in the form of calcium fluoride as Loewi expected.

0.001-0.01 M. fluoroacetate diminished significantly the oxygen consumption with the elevation of blood lactate and pyruvate level at the end of 2 hours perfusion and the augmentation of glucose uptake, while no diminution of the cardiac output. However, when the initial oxygen consumption is close to the level of the warm blooded animal by elevation of the environmental temperature and the heart rate, the cardiac output falls down simultaneously with the depression of the oxygen consumption. It is concluded that the glycolysis is sufficient enough for supplying the energy for the ordinary cardiac function but not enough for the excessive energy demand.

I am indebted to Mr. Y. Matsuyama for the chemical analysis, Miss Y. Sekiguchi and Miss Y. Kumazawa for preparing the manuscript.

\section{REFERENCES}

1) Hashimoto, K. And Nukada, A. Jap. J. Physiol. 1: 332, 1951.

2) Hashimoto, K., Morita, Y. and Matsuyama, S. Jap. J. Physiol. 8: 148, 1958,

3) Ellis, S. J. Pharmacol. et Exp. Therap., 109: 233, 1953.

4) BING, R. et al, Am. J. Med., 15: 284, 1953.

5) Goodale, W. T. And Mackel, D. B. Circulation Research, 1: 509, 1953.

6) Chenoweth, M. B. and Pengsritong, K. Fed. Proc., 9: 263, 1950.

7) Shigei, T. and Hashimoto, K. Jap. J. Pharmacol., 9: 109, 1960.

8) Racker, E. AND WU, R. Ciba Foundation; Symposium on the Regulation of Cell Metabolism. Churchill (London) 1959.

9) Meyerhof, O. ANd Schulz, W. Biochem. Z., 297: 60, 1938.

10) Kumagai, K., EBASHI, S. AND TAKedA, F. Nature, 176: 166, 1955.

11) LowwI, O. Pharmacol. J. et Exp. Therap., 114: 90, 1955.

12) Benett, D. R. ANd Chenoweth, M. B. J. Pharmacol. et Exp. Therap., 106: 373, 1952.

13) Hashimoto, K., Shigei, T., Morita, T. and Matsuyama, S. Folia Jap. Pharmacol., 52: 559, 1956.

14) Katzung, B., Rosin H. And Schneider, F. J. Pharmacol. et Exp. Therap., 120: 324, 1957. 